\title{
Miniaturized Microstrip Patch Antenna for Microwave Imaging Application
}

\author{
Priyanka.R, Manikandan.T, Joshua kumaresan. S, Muruganandham. A, Karthik.S
}

\begin{abstract}
This paper present the brief view to design of a microstrip rectangular patch antenna. Microstrip patch antennas are used because of configuration such as low profile, conformal, light weight, and easy fabrication. The linear polarization and circularly polarization of microstrip patch antennas have attracted more attention recently. These antennas are significant due to their ability to improve the benefits of microwave imaging application. The Federal Communication Commission (FCC) has approved the frequency limit for narrowband and wideband antenna. One of the advantage of the narrow band technology is the design of feasible compact conformal antennas. Therefore a compact miniaturized microstrip rectangular patch antenna has been proposed to design for microwave imaging application. The miniaturization of microstrip patch antenna has been done to obtain the better narrow bandwidth, return loss and Voltage Standing Wave Ratio (VSWR). Ultra Wide Band (UWB) is achieved by using certain techniques which is used for expansion of bandwidth. The rectangular patch antenna with a $50 \Omega$ microstrip feed is fabricated on the FR4 substrate.
\end{abstract}

Index Terms: MSA, return loss, VSWR, bandwidth, UWB

\section{INTRODUCTION}

$\mathrm{M}$ icrostrip rectangular patch antenna is preferred and choosen because of their specification such as low profile and conformal structure. Microstrip patch antennas have advantages like low profile, compatibility with planer as well as non planer surfaces, suitable for multi frequency operation and simplicity of manufacturing [3]. Microstrip patch antennas are widely used in compact devices such as mobile phones, laptops, USB dongles based $\mathrm{n}$ wireless communication etc., and Microstrip patch antenna plays an important role for the miniaturization of these devices [6].

At lower frequencies the size of the microstrip antennas becomes large band technology. The radiating patch and ground plane. [3]. The metallic patch can take many configuration 1. Rectangular patch 2. circular patch. There are variety of techniques are used to reduce the size of the microstrip antennas. A most important technique used to reduce the size of a patch is to eliminate one of the radiating

* Correspondence Author

Priyanka. R*, Assistant Professor, Department of ECE, Saveetha School of Engineering, Mail id: priyankar.sse@saveetha.com

Manikandan. T, Professor, Department of ECE, Rajalakshmi Engineering College, Mail id: manikandan.t@rajalakshmi.edu.in

Joshua kumaresan. S, Associate Professor, Department of ECE, R.M.K. Engineering College, skn.ece@rmkec.ac.in

Muruganandham. A, Professor, Department of ECE, Rajarajeswari College of Engineering Bangaluru, a.muruganandham@gmail.com

Karthik. S, Assistant Professor,Department of ECE, Sri Krishna College of Engineering and Technology, Coimbatore, kathikheyram@gmail.com
Revised Manuscript Received on November 12, 2019.

edges with a circuit [5]. However, there are certain limitations in designing of a microstrip antennas due to its narrow bandwidth. These types of microstrip patch antennas are popularly known as 'printed resonant antenna' and are used for narrow-band microwave wireless link [6]. Generally, rectangular and circular microstrip patches are commonly used for simplest and demanding applications.

\section{DESIGN OF MICROSTRIP PATCH ANTENNA}

Initially a microstrip patch antenna is designed. The antenna with a dielectric substrate of height ' $\mathrm{h}$ ', relative dielectric constant $\varepsilon r$ and antenna operating frequency fr. The efficient antenna design parameter is calculated by,

$\mathrm{W}=\mathrm{c} / 2 \mathrm{f}[(\in \mathrm{r}+1) / 2]-1 / 2$ and $\mathrm{L}=\mathrm{c} / 2 \mathrm{f} \sqrt{ } \in \mathrm{e}-2 \Delta \mathrm{l}$

W here, $\in \mathrm{e} \Delta \mathrm{l}$ can be calculated from [8].

\section{A.Radiation pattern}

The radiation pattern of microstrip miniaturized rectangular patch antenna is a half wavelength long. The fringing at both side of the patches are responsible for radiation pattern.

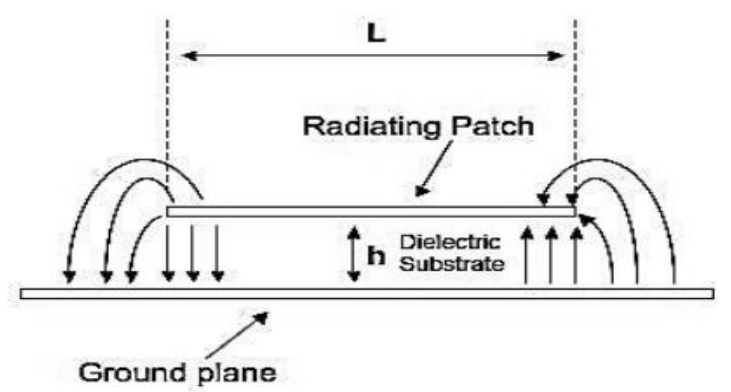

Fig. 2 Fringing field

\section{PROPOSED SYSTEM}

The proposed system is based on designing of miniaturized microstrip rectangular patch antenna for microwave imaging applications. The proposed antenna is designed to achieve the narrowband and wideband frequency approved by the FCC. The Computer Simulated Technology software can be used for the design purpose. Miniaturization is done by size reduction of the microstrip rectangular patch antenna to attain the better narrowband and wideband is obtained by introducing slots in the ground rectangular plane. 


\section{SIMULATION RESULT FOR NARROWBAND}

\section{A. Microstrip patch}

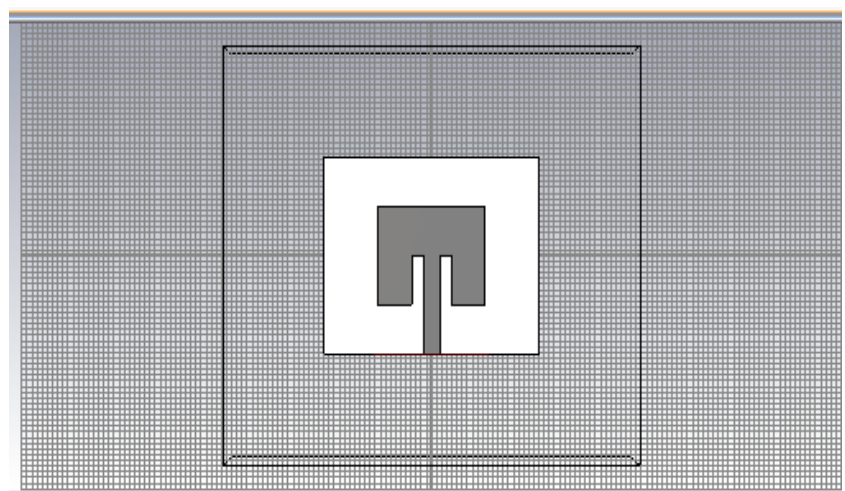

Fig. 3 Front view of MSA

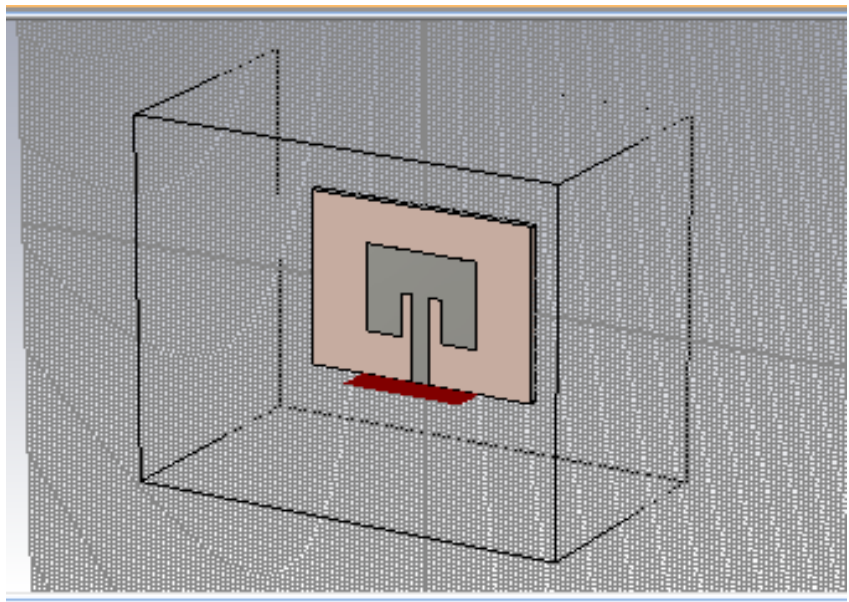

Fig. 4 Perspective view of MSA

\section{B. S Parameter}

$\mathrm{S}$ parameter is calculated based on the reflection coefficient of the microstrip patch antenna. This parameter explains the amount of an electromagnetic waves is reflected by an impedance matching discontinuity in the transmission range. The representation of $s$ parameter of microstrip patch made of dielectric substrate FR-4 material.

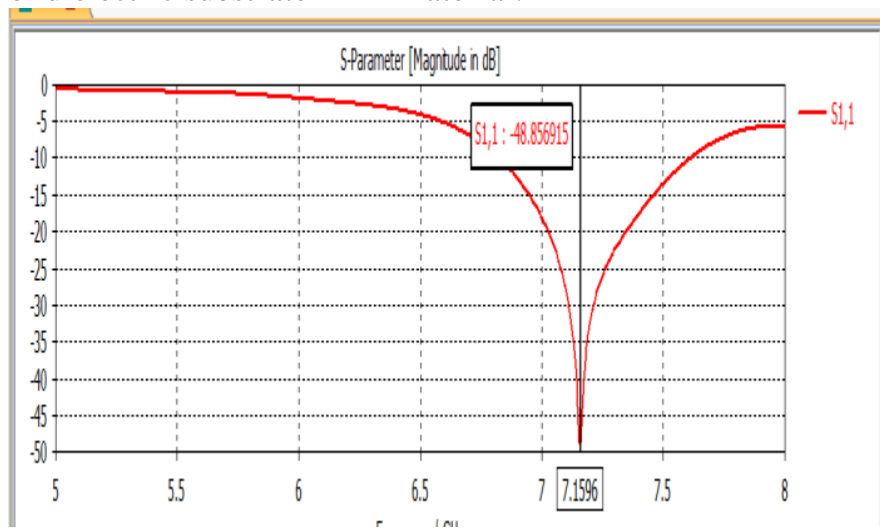

Fig. 5 S Parameter of MSA

A rectangular patch antenna fed by microstrip line has been designed and obtained $7 \mathrm{GHz}$ resonant frequency and VSWR of 1.061 and return loss of about- $48.8 \mathrm{db}$. Miniaturization can be done by size reduction of the rectangular patch. The range of VSWR has to be less than 2 denotes that impedance matching between the transmitter and the receiver. Return loss denotes the amount of power reflected from the antenna resonant frequency denotes the radiation.

\section{VSWR and return loss}

Voltage Standing Wave Ratio (VSWR) is a function of reflection coefficient which describes the power reflected or radiated from the antenna. The various parameters such as VSWR, RETURN LOSS is represented here.

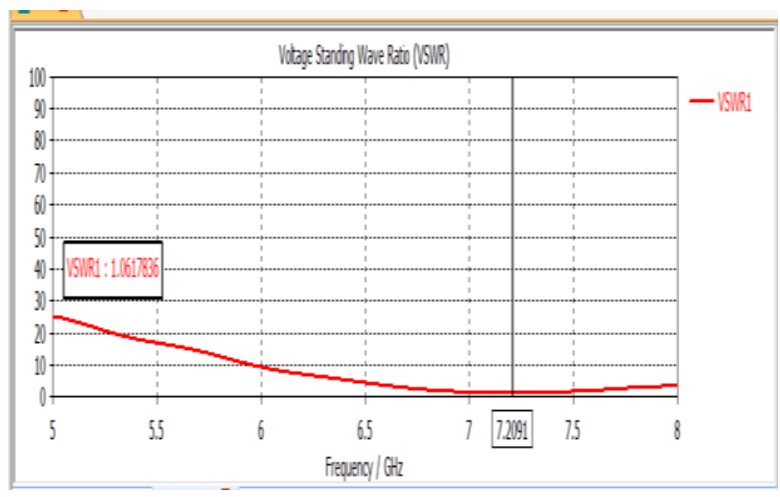

Fig.6 VSWR of MSA

VSWR is the measure of impedance matching of source loads to the characteristics impedance of the transmission line. VSWR should be less than 2 denotes the better performance of the antenna.

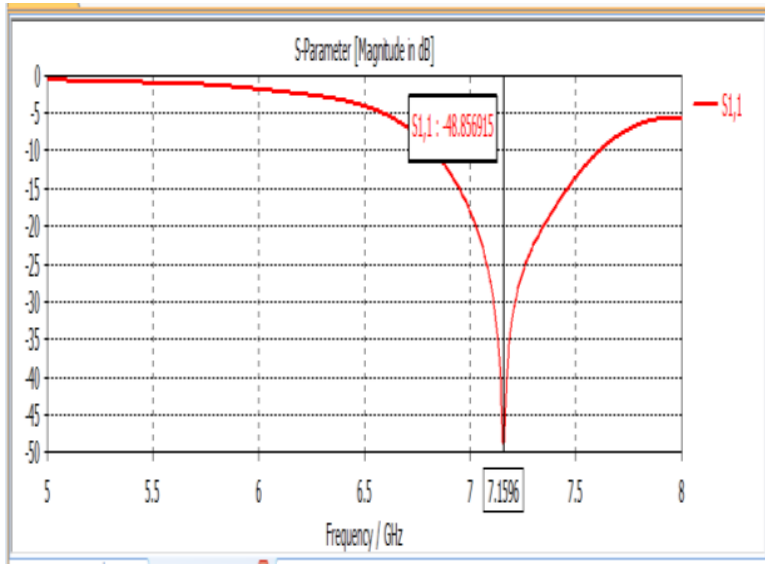

Fig. 7 Return loss of MSA

\section{V . ULTRAWIDE BAND}

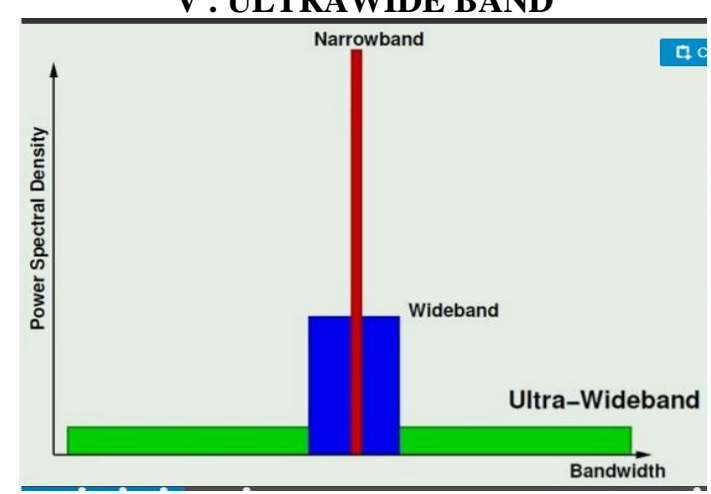

Fig. 9 Frequency Band

Published By:

Blue Eyes Intelligence Engineering 


\section{SIMULATION OUTPUT FOR UWB}

\section{A .Reduced Ground Plane}

Ultra wide band is achieved by various techniques and one of the method is reduced ground plane. Ground plane reduction is achieved by reducing the length of the ground in the microstrip patch antenna to the minimum in this some bandwidth enhancement will be obtained. Microstrip patch antenna is narrow band antenna because the radiation will occur only on both the side of the patch. By reducing the ground plane the entire patch will radiate this will improve the bandwidth. The reduced ground plane is shown in the below fig.

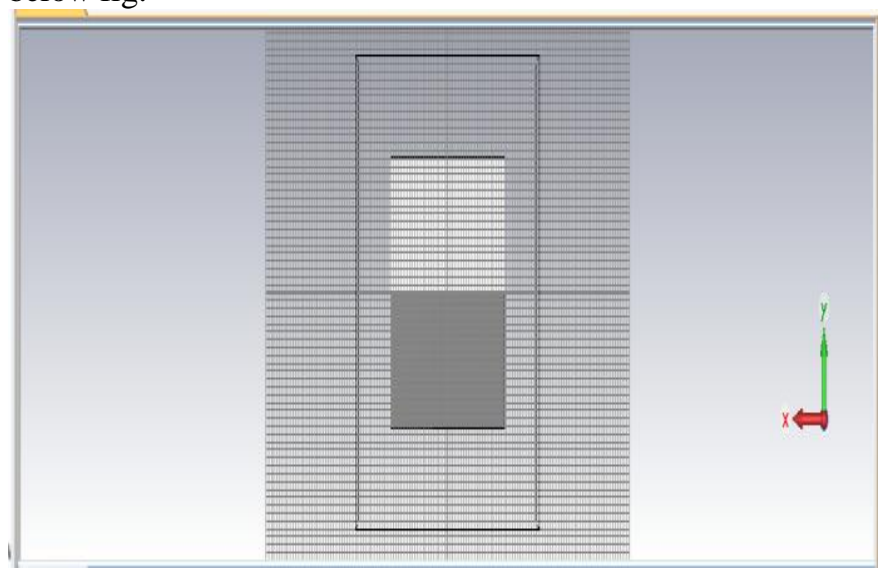

Fig. 10 Reduced Ground plane of MSA

\section{B. Slotted ground plane}

Ultra wide band is achieved by various making the slot in the ground plane of the microstrip rectangular patch antenna. Microstrip patch antenna is narrow band antenna because the radiation will occur only on both the side of the patch. By introducing the slot in ground plane the entire patch will radiate this will improve the bandwidth. The slot introduced antenna is shown in the below fig.

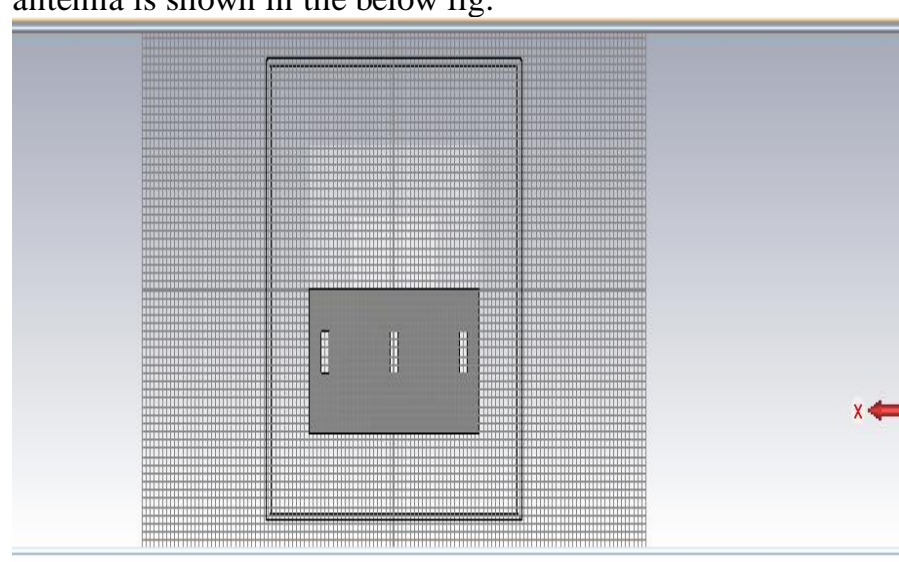

Fig. 11 Slotted ground plane

\section{UWB S PARAMETER}

S parameter based on the reflection coeffiecient of the designed antenna. This parameter describes how much of an electromagnetic waves is reflected by an impedance discontinuity in the transmission medium. The representation of s parameter of microstrip patch made of dielectric substrate FR-4 material is shown in Fig

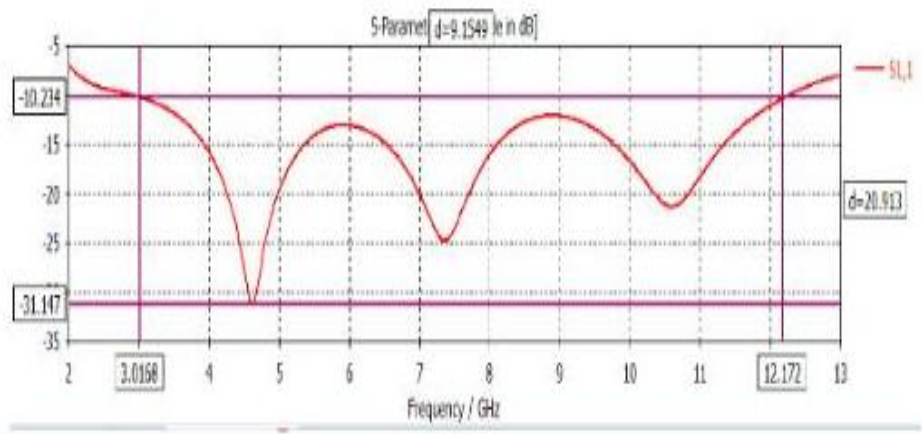

Fig. 11 Resonant Frequency

Bandwidth enhancement technique such as slot introduction increases the bandwidth up to $30 \%$ and then increasing the substrate thickness also increases the bandwidth to achieve the ultra wide band frequency. Introducing partial ground and then reducing the dielectric constant both of these increases the fringing filed and then increases the resonant frequency. Accurate Ranging information, Radar and Imaging

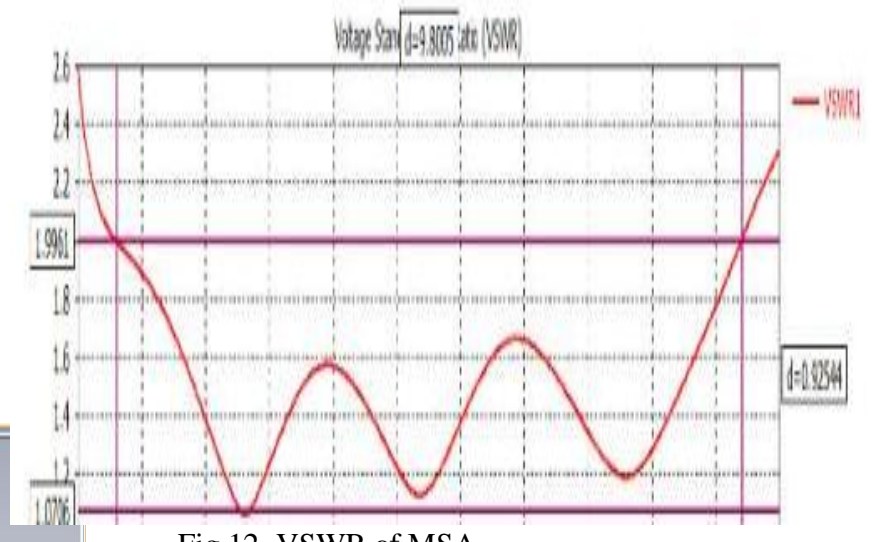

Fig 12. VSWR of MSA

\section{CONCLUSION}

The microstrip patch antenna is narrowband antenna, so work has been done to miniaturize the microstrip patch antenna by reducing the size to increase the bandwidth of the antenna. The performance analysis of rectangular microstrip antenna for narrowband application has been done in current work. Firstly, a rectangular patch antenna fed by microstrip line has been designed and obtained $7 \mathrm{GHz}$ resonant frequency and VSWR of 1.061 and return loss of about- $48.8 \mathrm{db}$. Ultra wide band is achieved $3-12.1 \mathrm{GHZ}$ of resonant frequency and VSWR of 1.996. 


\section{Miniaturized Microstrip Patch Antenna for Microwave Imaging Application}

\section{REFERENCES}

1. Ali Araghi and Gholamreza Dadashzadeh (2012) 'Oriented design of an antenna for MIMO Applications using Theory of characteristic modes' IEEE antennas and wireless propagation letters, Vol 11, pp.1040-1043

2. Jui-han Lu,Chia-Luan Tang,and Ki-lu Wong (1999) 'UWB Omnidirectional Square Antenna for Microwave Imaging Systems. Polarization', IEEE transactions on antennas and propagationVol.47, No.7, pp.1174-1178

3. R.Srilakshmi, T.Manikandan and Shaikh Thasleem Banu, 'Performance Comparision of S-Band Antenna Array with Series fed and Corporate fed Microstrip Array', International Journal of Engineering and Technology, Vol.7(2.33), 2018, pp. 1036-1039.

4. Lim.E.G, Korolkiewicz.E, Scott.S,Sambell.A and Aljibouri .B (2002), 'An Efficient Formula for the input Impedance of a Microstrip Right-Angled Isosceles Triangular Patch Antenna', IEEE antenna and wireless propagation,Vol.1,pp.18-21.

5. Lin,Y.-C. Kuo and H-R .Chuang (2005) 'A Planar Triangular Monopole Antenna for UWB Communication', IEEE microwave and wireless components, Vol.15, No.10, pp.624-626.

6. V. Nandalal, V. Anand Kumar, T. Manikandan, 'Performance Evolution of Reconfigurable Antenna using Contact and Non-Contact feeding Technique', in Proc. of 3rd Int. Conf. Electronics Communication and Aerospace Tech., ISBN: 978-1-7281-0167-5, 2019, pp.952-954.

7. Iti Saha Misra and Chowdary.S.K (1998), 'Study of Impedance and Radiation Properties of a Concentric Microstrip Triangular-Ring Antenna and its Modelling Techniques Using FDTD Method', IEEE transactions on antennas and propagation,Vol. 46,No. 4,pp.531-537.

8. Jeen-Sheen and Yen-Yu Liou (2006), 'Broadband of Short-Circuited with Triangular Patch Antenna', IEEE transactions on antennas and propagation, Vol. 5,No.7,pp.237-2141.

9. Jieh-Sen Kuo and Gui-bin Hsieh (2003), 'Gain Enhancement of a Circularly Polarized Triangular Microstrip Antenna with a slotted plane', IEEE transactions on antennas a propagation, Vol. 51, No.7,pp.1652-1656.

10. Jui-han Lu,Chia-Luan Tang and Kin-Lu Wong (2000), 'Microstrip Patch Antenna for UWB Applications', IEEE transactions on antennas and propagation, Vol.48,No.7,pp.1048-105.

\section{AUTHORS PROFILE}

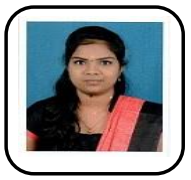

R.Priyanka is a Assistant Professor working at Saveetha School of Engineering Chennai. She is currently pursuing her Ph.D in Saveetha School of Engineering since 2018. She pursued her B.E Degree in Electronics and Communication Engineering from Jaya Engineering College in 2015 and M.E degree in Applied Electronics from R.M.K Engineering College in 2017. She is having teaching experience of 2 years. Her area of research includes Machine learning and Artificial Intelligence. She also guided many projects at UG level.

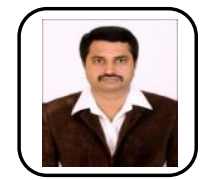

Dr. T. Manikandan is a Professor working at Rajalakshmi Engineering College, Thandalam, Chennai. He has completed his Ph.D titled "A study on computer-aided diagnosis systems for lung cancer detection and its three dimensional visualization using machine learning techniques" at Anna University, Chennai during January, 2017. He did his bachelor's degree in Engineering from Vellore Engineering College, Chennai under Madras University \& master's degree in Engineering from College of Engineering, Anna University, Guindy, Chennai during 1998 \& 2007, respectively. He is having 21 years of teaching experience which includes both UG and PG. He also guided many projects at UG \& PG levels. He has 50 papers in refereed international journals and conferences in his credit. He is serving as editorial board member for various international journals such as International journal of Biomedical and Healthcare Sciences, Archives of General Internal Medicine, Journal of Cancer Diagnosis, Journal of Medical and Clinical Oncology, Journal of Clinical Epigenetics and Integrative Cancer Biology and Research.

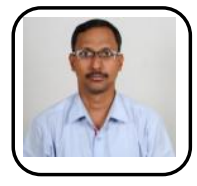

Dr.S.Joshua Kumaresan is working as Associate professor in the department of ECE of R.M.K. Engineering college. He completed his Ph.D in the area of image processing in 2018, M.E (VLSI Design) in 2007 both from Anna university Chennai. He also completed M.S (Electronics and Control) from BITS, Pilani in 1999 and B.E (ECE) in 1994 from Bharathidasan University. He has 23 years of teaching experience which includes both UG and PG. and 1 year he worked in an industry as R\& D
Engineer. He published more than 20 papers in international journal and conferences.He published books on Electromagnetic Fields, Digital Electronics, Digital Principles system design and Digital logic circuits. . He guided many projects at UG \& PG levels. He also mentored and guided many students for various competitions like Smart India Hackathon, Arm design contest, India Innovation challenge design contest 2018 etc. He organized many college level National conferences and symposiums. He is a member of professional societies IEI, ISTE, ISRO-ISSE, and IACSIT.

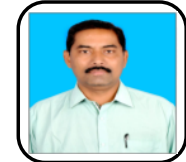

Dr. A. Muruganandham received the B.E. Degree in Electronics and Communication Engineering and M.E., degree in Communication systems from University of Madras and National Institute of Technology (NIT), Trichy in 1993 and 2000, respectively. He completed the Ph.D (Image Compression) degree in Anna University in the year 2013, Chennai. He is a life member of ISTE, FIE and member of IEEE. He is currently working as a Professor in the Department of Electronics and Communication Engineering, at Rajarajeswari College of Engineering, Bengaluru, Karnataka, India and has a teaching experience of 23 years. His-research interests includes Image processing and Bio Medical Engineering.

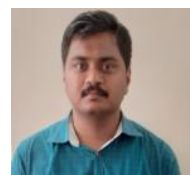

Karthik S, received the B.E degree in electronics and communication engineering from Coimbatore Institute of Technology, Coimbatore, in 2009 and received the M.E degree from Anna University Coimbatore in 2011. Having more than 8 years of teaching experience, he is currently an Assistant Professor with Sri Krishna College of engineering and technology, Coimbatore. His research interests include electromagnetics, communication systems and wireless sensor networks

Email: karthikheyram@gmail.com 